\title{
Research Progress of Phase Change Materials
}

\author{
Hongyan Zhang ${ }^{1, \text { a }}$ \\ ${ }^{1}$ Chemistry and Chemical Engineering \& Environmental College, Weifang University, Weifang, \\ Shandong, China \\ azhanghy@wfu.edu.cn
}

\begin{abstract}
Keywords: Research; Phase Change Microcapsule; Phase Change Material; Inorganic Phase Change Material; Organic Phase Change Material
\end{abstract}

\begin{abstract}
With the increasing of the traditional energy, the utilization of traditional energy and new energy researching is an important direction for the development of the new era. Phase change material, is a new era for the sustainable development of new energy research. The phase change material wrapped into microcapsules is an effective way of heat storage.
\end{abstract}

\section{Introduction}

Now with the rapid economic development, social demand for energy is getting higher and higher, and now use the main energy sources of non-renewable energy accounted for almost $90 \%$, of which the largest oil, 37.4\%. It is essential to improve the efficiency of energy use and to develop new energy sources for the sustainable development of society. Phase change material microcapsules, is a new era of sustainable development for the study of new energy. The use of a stable material as a wall material, the phase change material wrapped in the inside, so that the formation of the core structure of microcapsules, which is phase change material encapsulation technology. Microencapsulation technology can effectively prevent the phase change material leakage problem, and can make the phase change material at the appropriate temperature and time to change the phase. Microcapsule technology broadens the application of phase change materials. The encapsulated phase change material can be applied not only to the field of textiles and garments, but also to the fields of construction, military and transportation. Microencapsulation technology can give phase change materials more function. In this paper, we mainly study the phase change material of n-octadecane / urea-formaldehyde resin microcapsule, which can improve the energy utilization rate and improve the energy utilization rate by the high temperature endothermic and low temperature heat dissipation through its own temperature control effect.

\section{Phase Change Material Definition}

Phase change material in the broad sense is in the phase change occurs when the absorption or release of a certain latent heat of the material, phase change material in the narrow sense it is in a shorter time and temperature range phase changes occur, and can release or absorb a certain amount of heat. The phase change has four different states: the change of the solid into a liquid state, the change of a solid into another solid state, the liquid becomes a solid, and the liquid becomes a gas [3].

\section{Phase Change Material Classification}

Based on the state of phase change of phase change material, the following classification is carried out: solid-gas phase change material; liquid-gas phase change material; solid-liquid phase change materials; solid-solid phase change material.

Among the phase change materials described above, solid-gas phase change materials and liquid-gas phase change materials have many drawbacks, for example, they tend to cause significant volume changes in the event of phase changes, and their utilization rates are not high. Solid-solid phase change material in the phase change occurs, there is no liquid and gas phase, so that the phase change of the volume changes and undercooling are very small, but also lead to its cycle of life cycle of inorganic salts 
and polyhydric alcohols are all solid-solid phase change materials, but the solid-solid phase change materials research and development time is not long, the theoretical research is far less than solid-liquid phase change materials, so solid - liquid variable materials are more widely used.

Phase change material is in the absence of chemical changes only state changes can absorb or release a lot of phase change enthalpy of the material $[4,5,6,7]$. In the field of heat storage and temperature control is widely used in recent years in Europe and the United States and other developed countries, particularly fast research and development. Organic and inorganic phase change materials have their own advantages and disadvantages, inorganic phase change material has the advantage of melting heat, phase change small size, high thermal conductivity, the disadvantage is the process of supercooling, phase separation. Similarly, the organic phase change material has the advantage of a suitable temperature phase transition, a large latent heat, the disadvantage is the phase change process heat transfer performance is relatively poor, thermal conductivity is relatively low, and some organic phase change material performance is unstable, some liquid phase leakage and so on. So there have been phase change heat storage composite materials [8].

\section{Inorganic Phase Change Materials.}

Gold or alloy, molten salt [9] and crystalline hydrate [10,11], crystalline hydrate are the most common inorganic phase change energy storage materials. Inorganic phase change material has the advantage of melting heat, small phase change volume, high thermal conductivity. The disadvantages of inorganic phase change materials are "phase separation" and "super cooling". So the inorganic phase change material also use anti-cold refrigerant, anti-cold refrigerant than the inorganic phase change material melting point higher than the cold tendency and the nature of the composition and inorganic phase change material similar to the inorganic phase change material phase separation also need to join a certain amount of thickener and crystal modifier. A lot of work have been done before the study of crystalline hydrates, such as iron, aluminum, zinc, manganese and other phosphate, such as sulfate and nitrate different crystal water and salt research. And its melting point and latent heat of phase change were measured by experimental analysis, and it was also verified whether it could be used as phase change material to store heat.

\section{Organic Phase Change Materials.}

There are straight chain alkanes, alcohols, fats and so are more common organic phase change materials. The preparation of paraffin is through the petroleum industry cracking, refined, it is a mixture of several linear paraffins, its general formula is $\mathrm{CnH}_{2 n+2}$. The latent heat of the phase change is due to the difference in the number of carbon atoms. The number of carbon atoms in the paraffin is generally 10-50, and the latent heat of the paraffin has a more complicated variation. In general, if the alkane contains even carbon atoms, the latent heat of its phase change increases due to the increase in the number of carbon atoms. However, if the alkane contains an odd number of carbon atoms, its latent heat of transformation is difficult to find. Paraffin wax compared with other phase change materials, or has a lot of advantages. For example, paraffin is a mixture of several linear alkanes. The latent heat and phase transition temperatures have a wide range. The paraffin has stable chemical properties and its price is relatively low. Paraffin wax does not cause corrosion to the container because of its $\mathrm{pH}$ was neutral. The same paraffin also has a low thermal conductivity of the shortcomings, in order to improve its shortcomings, many people have done a lot of research, the improvement of the method in the paraffin added thermal conductivity material to improve the thermal conductivity of the container area, the use of porous media of the heat storage container.

The so-called polyol phase change material is also a solid-solid state, and now the polyol phase change material research is very much, including trimethylol ethylene (PG), 2-amino-2-methyl-1,3 - propylene glycol (AMP) and trimethylol aminomethyl (TAM). Their advantages are relatively stable performance, long life, smaller supercooling, but there are disadvantages of heating the phase transition temperature above the plastic crystals that have great vapor pressure and are sublimable and must be sealed with a closed pressure vessel. And the superiority of solid-solid phase change materials can not be revealed. In order to solve the heat problem, we mix two or more polyols in a certain proportion to form an alloying "alloy" [12] to adjust the temperature of the phase change to obtain the temperature we need. Because 
of high and the latent heat of the phase change temperature, polyol material is widely used in the high temperature area, and the low temperature area is not applicable.

Polymer material is not complete crystal, the molecular chain is very long and is the melting range of temperature phase transition process, in the temperature storage is very suitable. Polymer materials are different solid-solid phase change materials, with a relatively small phase change volume, will not appear liquid phase, to solve the problem of such materials easy to flow and discharge. In the polymer materials to polyethylene glycol (PEG) class study more [13].

Fatty materials are less latent heat than paraffin, and can be crystallized and melted repeatedly, and there is no phase separation and supercooling, but the cost is relatively high. Sair et al. [14] tested the thermal stability of fatty acids through a series of experiments, including dodecanoic acid, lauric acid, palmitic acid and stearic acid. Experiments show that, after one hundred twenty to one hundred and twenty hundred cycles of latent heat changes in the range of 1.1-26.9\%, the temperature range is $0.068-7.78{ }^{\circ} \mathrm{C}$. It can be seen that fatty acids have good thermal stability as phase change heat storage materials.

\section{Comparison of Organic Phase Change Materials and Inorganic Phase Change Materials.}

Most of the most original heat storage materials in the low cost, easy to prepare inorganic compounds in the study, but later in the application of corrosive, phase separation and other deficiencies, repeated use of material spillover and changes in irregular and other issues, so that the application Limited. Organic phase change materials can solve the shortcomings of inorganic phase change materials, and thus make the organic phase change materials are concerned by the majority of researchers. Their advantages and disadvantages of contrast and improvement methods [15] as shown in Table 1.

Table 1 Advantages and disadvantages of inorganic phase change materials and organic phase change materials and improvement methods

\begin{tabular}{|c|l|l|}
\hline \multirow{5}{*}{ The advantages } & Inorganic class & Organic class \\
\cline { 2 - 3 } & low price & without corrosion, safety \\
\cline { 2 - 3 } & high single volume latent heat & stable chemically \\
\cline { 2 - 3 } & high point of fire & no separated and too cold \\
\cline { 2 - 3 } & high Thermal conductivity & $\begin{array}{l}\text { phase transition temperature } \\
\text { range, optional and more }\end{array}$ \\
\cline { 2 - 3 } & small phase change & $\begin{array}{l}\text { good traditional material } \\
\text { compatibility }\end{array}$ \\
\cline { 2 - 3 } Disadvantages & large phase separation corrosive & $\begin{array}{l}\text { low single volume phase } \\
\text { transition potential }\end{array}$ \\
\hline Improve the method & $\begin{array}{l}\text { low thermal conductivity when } \\
\text { solid } \\
\text { flammable }\end{array}$ \\
\hline & $\begin{array}{l}\text { adding anti-phase separator and } \\
\text { anti-cold refrigerant }\end{array}$ & $\begin{array}{l}\text { adding flame retardant and } \\
\text { thermal conductivity agent }\end{array}$ \\
\hline
\end{tabular}

\section{References}

[1] H.T. Cui, F. Yang: Technology and application of thermal storage (Chemical Industry Press, China, 2004), P.214.

[2] C.X. Guo, X.L. Wei: Technology and application of thermal energy storage (Chemical Industry Press, China, 2005), P.65.

[3] Y.P. Zhang, H.P. Hu: Theory and application of phase change energy storage (Press of University of Science and Technology of China, China, 1996), P.25. 
[4] Q.H. Zhuang, and Z.G. Zhang: Preparation and application of micro-encapsulated/ nano-encapsulated phase change materials, Chemical Industry and Engineering Progress, Vol. 25 (2006) No.4, p.388.

[5] W.P. Xie, N. Wang, D.S. Zhu, and X.J. Wang: Review of heat transfer enhancement of the PCMs, Chemical Industry and Engineering Progress, Vol. 27 (2008) No.2, p.190.

[6] Z.G. Zhang, X.Z. Wang, and X.M. Fang: Structure and Thermal Properties of Composite Paraffin /Expanded Graphite Phase-Change Material, Journal of South China University of Technology(Natural Science Edition), Vol. 34 (2006) No.3, p.1.

[7] J.P. Wang, and X.X. Zhang: Recent Progress in Microencapsulated Phase Change Materials, Materials Review, Vol. 21 (2007) No.4, p.107.

[8] Z.G. Zhang, J. Wen, X.M. Fang, G. Shao, and Y.F. Huang: Research and Development on Composite Phase Change Thermal Energy Storage Materials. Chemical Industry and Engineering Progress, Vol. 22 (2003) No.4, p.462.

[9] B. Zalba, J.M. Marin, and L.R. Cabeza: Review on thermal storage with phase change: materials, heat transfer analysis and applications, Appl Therm Eng, Vol. 23 (2003) No.3, p.251.

[10] A.Y. Chen, X.Y. Wang, and X.Z. Cao: Research and Application of Phase Change, Materials Review, Vol. 17 (2003) No.5, p.42.

[11] H.B. Cai, A.Z. Shui, L.K. Zeng, X.S. Cheng, H. Wang, P.A. Liu, Y.W. Zhang: Research Status and Prospects of New Phase Change Materials, Journal of Ceramics, Vol. 29 (2008) No.4, p.379.

[12] H. Nakada, M. Kubota, and F. Watanabe: Estimation of melting point/latent heat of binary mixtures of phase change material of erythritol and polyalcohol, Kagaku Kogaku Ronbun, Vol. 32 (2006) No.5, p.429.

[13] J.C. Su, and P.S. Liu: A novel solid-solid phase change heat storage material with polyurethane block copolymer structure, Energ Convers Manage, Vol. 47 (2006) No.18, p.3185.

[14] A. Sari: Thermal reliability test of some fatty acids as Pecks used for solar thermal latent heat storage applications, Energ Convers Manage, Vol. 44 (2003) No.17, p.2277.

[15] X.Wang, Y.P. Zhang, and W. Xiao: Review on thermal performance of phase change energy storage building envelope, Chinese Sci Bull, Vol. 54 (2009) No.6, p.920. 